\title{
Brain Disorder
}

National Cancer Institute

\section{Source}

National Cancer Institute. Brain Disorder. NCI Thesaurus. Code C96413.

A non-neoplastic or neoplastic disorder that affects the brain. 